\title{
Spatial Models for Identifying Factors in Student Academic Achievement
}

\author{
Filiz Akbas-Yesilyurt (D) 1, Huseyin Kocak ${ }^{(D 2}$ 2, M. Ensar Yesilyurt (i) 1,*
}

${ }^{1}$ Pamukkale University, Department of Economics, Denizli, Turkey

${ }^{2}$ Pamukkale University, Department of Business Administration, Quantitative Methods Division, Denizli, Turkey

\section{ARTICLE HISTORY}

Received: Apr. 18, 2020

Revised: Sept. 09, 2020

Accepted: Nov. 09, 2020

\section{KEYWORDS}

Student achievement, Interaction,

Spatial models

Abstract: In the literature, estimation results of the determinants of academic achievement are controversial. There may be several reasons for these controversial results, including sample or cultural differences. Conversely, these results may arise from ignoring certain important facts, such as an interaction effect. Some studies do not consider interactions among students, and some studies may not use effective models. Surprisingly, very few studies have focused on student academic achievement using spatial models, which may be one of the most suitable models for testing interaction effects. In this study, we estimated student achievement using spatial models and a data sets from Turkey. We observed an interaction between students who live in the same neighbourhood and found evidence of an interaction among students in terms of their achievement based on a spatial error model.
\end{abstract}

\section{INTRODUCTION}

The question of whether students' academic performance is "contagious" is a very old debate in the literature. For example, Bronfenbrenner's (1994) ecological systems theory, although not focused solely on student achievement, examines a child's development within the context of the system of relationships that form the child's environment. Similarly, some theories and discussions of "social interaction", "correlation between students", and the "peer effect" in schools and neighbourhoods have been presented by Manski (2000), Akerlof (1997), Bayer et al. (2008), Bernheim (2004) and Winship et al. (2011). This literature assumes that interaction effects also influence individual behaviour or outcomes due to the characteristics of students (Deitz, 2002) and agrees that students interact with each other depending on the specific environment in which they live (Mayer \& Jencks, 1989).

Other important issues related to interaction among students are the measurement of interaction and econometric and data issues. For example, Manski (1993 and 2000), Moffitt (2001) and Brock and Durlauf (2001) discussed the estimation of social interaction effects. They suggested that the outcome for an individual in a group is affected by individual characteristics, the outcome of the group and exogenous and predetermined characteristics. However, conventional models cannot capture these effects in estimations that focus on social interaction. Many attempts have been made to capture these effects. For example, some researchers have used the 
instrumental variable method (Aaronson, 1998), group fixed effects (Evans et al., 1992; Lavy \& Schlosser, 2011), experimental formations (Moffitt, 2001; Zimmerman, 2003), specific dummies (Jensen \& Harris, 2008; Sykes \& Kuyper, 2009; Gould et al., 2009; Aslund et al., 2011; Weinhart, 2014; Gibbons et al., 2013), multilevel models (Brannstrom, 2008), logistic regression (Adejoro, 2016) and peers' features (Brooks-Gunn et al., 1993) to understand, capture and measure peer effects and interaction. However, in studies that do not consider interaction, interactions with some dissimilar characteristics are considered equivalent (Dietz, 2002), which might produce biased results.

How interaction effects can be measured and compared is an important issue (Duncan, 1994; Brannstrom, 2008). Although a powerful theoretical structure is included in the publications that consider interaction effects (Manski, 1993; Elhorst, 2010; Elhorst et al., 2013), spatial models are not common in studies of the effects of student interaction on student achievement Even though dummies represent the effect of similarities, spatial models may represent additional information, such as the type and level of interaction, direct and indirect linkages and a holistic interaction. On the other hand, as noted by Hsieh and Lin (2019), who were among to use spatial models of student achievement, "the literature on social interactions has mainly focused on the influences of peers on behaviors and decisions of an individual, rarely considering the possible formation of social preferences among the network links". Other examples use spatial models to estimate student achievement (Matlock et al., 2014; Zangger, 2016).

In this context, the present study focuses on estimating student achievement by considering interaction effects using data sets for high school students from Turkey. With the aim of investigating the influence of spillover effects on students' achievements, we test the following hypothesis associated with the assumptions using spatial models: We test whether student achievement is affected by neighbouring students' achievements as our first hypothesis and whether students' performance is influenced by neighbouring students' achievements and the performance of individual, environmental and family neighbouring effects as our second hypothesis; for our third hypothesis, after controlling for the observed characteristics, we investigate whether students' achievements are influenced by unobservable factors (Zavarrone \& Vitali, 2012).

Since the present research is about Turkey Education System, a brief overview about development in Turkey Education System sheds light on the discussionis and as follows: The transformation of the education system in Turkey is not yet complete, and major changes occur frequently. Some important structures and processes are presented below (these are explained for the time period we analysed; since then, some new changes have occurred): a) Prior to 1999, the duration of primary school, secondary school and high school was 5, 3 and 3 years, respectively. This was changed to 4 years each. In 2005, primary school became 8 years long, and high school became 4 years long. Primary school is compulsory. These developments seem to contribute to educational output. For example, in 2013, while average years of schooling was 6.5 expected years of schooling was 11.5 (Yesilyurt et al., 2016). This finding indicates that the changes led to a significant improvement in the number of years that students were educated in schools. Improvements in quality are expected to increase with improvements in quantity. $b$ ) Because Turkey has a large youth population, students compete to enter university. Many students are eager to gain admission to and acquire a degree from a university. This structure has led to a demand that has surpassed the supply in higher education. After 2000, private universities were founded, and students could enter them more easily by paying a relatively high fee. Public universities are either free or require a very small fee. c) Two entrance exams are administered to students, who are ranked by their grade and assigned different types of points based on the public achievement index. In Turkey, university entry is based on general exams. The first-level exam is "Access to Higher Education (AHE)", and the second exam is 
the "University Attendance Exam (UAE)". The first exam selects and ranks students for the second exam, while the second exam directs students to the appropriate departments depending on their scores, their career plans and a portion of their first exam score. $d$ ) The scores from these two exams are not unique. Several types of scores constitute achievement in math, science or social science. For example, if students want to enter the faculty of medicine, they must apply with a good science score. In the first step, there are fewer types of scores. All students' scores cover the same questions and are comparable in the same score groups.

The contribution of this study is twofold. First, we use spatial models to test the above hypotheses. The use of spatial models to estimate student achievement is not common and occurs in a very limited number of studies. This approach may contribute to discussion in this field. Second, most studies in the spatial economics literature choose weight matrices subjectively. However, the results can change depending on the weight matrix. In this study, we use the Bayesian approach and traditional tests to choose the best-fitting weight matrix for the data. Recently, a similar idea was effectively used to determine factors in the development of towns in Turkey (Yesilyurt et al., 2020)

In the next sections, we introduce the education system in Turkey, the datasets, and the theoretical structure. The last two sections are dedicated to the estimation results and conclusions.

\section{METHOD}

In this section, we present the economic theory behind student achievement and the spatial econometric structure.

\subsection{Theoretical Structure}

The basic structure for determining student achievement is discussed in Hanushek (1979), Todd and Wolpin (2003) and Heck (2009) as

$S S=\mathrm{f}(S T D, F A M, S C H, E N V)$,

where SS, STD, FAM, SCH, ENV indicate the student achievement in AHE, the student's characteristics, the student's family characteristics, the student's school and the student's environment, respectively. The corresponding variable names with these categories are discussed in Section 3.2.

\subsubsection{Econometric model}

Econometric structure and their connection with the hypothesis are given below:

a) The hypothesis and spatial models:

In recent years, spatial interaction has become one of the most investigated topics in economics. In the literature, spatial heterogeneity and spatial dependence are the two sources of spatial relations. Spatial heterogeneity leads to parameter instability, and spatial dependence leads to correlation between the spatial units. Accounting for these effects with standard econometric techniques is fraught with a number of problems. In line with this study, Boarnet (1994) stated that small units create spatial dependence, which requires special treatment. Since the violation of assumptions is profoundly important, modelling spatial interaction properly is important. The basic modelling of the spatial interaction can be endogenous $(Y)$, exogenous $(X)$ and among the error terms $(\varepsilon)$. The general model with all the interaction effects (Vega \& Elhorst, 2015):

$Y=\alpha+\delta W Y+X \beta+W X \theta+u$,

$u=\lambda W u+\varepsilon$,

where $W$ is the weight matrix that evaluates the connections between economic units. $\delta$ is the spatial autoregressive coefficient, $\theta$ is the unknown parameter and $\lambda$ is the spatial 
autocorrelation coefficient. $W Y, W X$ and $W u$ indicate endogenous and exogenous interaction effects and interaction effects among the errors, respectively. If $\lambda$ and $\theta$ in the equation are equal to zero, the general model is reduced to a spatial autoregressive model (SAR). If $\delta$ and $\theta$ are equal to zero, the spatial error model (SEM) will be the true model while $\lambda$ is equal to zero, the spatial Durbin model (SDM) will be the true model.

Regarding the hypotheses considered in this study, if there is a spatial lag in the dependent variable, it is evidence of spatial autocorrelation (SAR) in students' achievements (i.e., there is confirmation of the first hypothesis). If spatial lags exist in the dependent and independent variables (spatial Durbin model-SDM), there is confirmation of the second hypothesis. If there is spatial lag in the error process (SEM), common unobserved factors affect student achievement, confirming the third hypothesis.

b) Specification tests:

The literature presents different approaches for choosing the correct weight matrix and the model. One of the most well-known and frequently used tests for investigating whether residuals are spatially correlated is Moran's $I$ test. Another common approach to test for spatial dependencies is the Lagrange multiplier tests.

Since the weight matrix is introduced the model a priori, some researchers note that building a weight matrix that shows how the contiguity relation is determined is one of the important steps (Paelinck \& Klaassen, 1979; Anselin, 1988). Alternatives can be used to achieve this outcome by comparing different weight matrices' parametric indicators (Ertur \& Koch, 2007), using a weight matrix that is noted by model diagnostic statistics (Stakhovych \& Bijmolt, 2009) or creating proxy variables to integrate spatial relations. However, these approaches may not prevent bias and inconsistencies due to the use of an incorrect weight matrix (Mizruchi \& Neuman, 2008; Farber et al,. 2008). In recent years, Bayesian model specification tests have become another method for comparing different weight matrices and spatial models for the best fit. This approach considers the log marginal likelihoods of the models. The highest probability will lead to the appropriate specification, and the estimator is not affected by specification error (Lesage, 2014; Lesage, 2015):

$\operatorname{prob}\left(M_{i} \mid y\right)=\frac{\operatorname{prob}\left(y \mid M_{i}\right) \operatorname{prob}\left(M_{i}\right)}{\operatorname{prob}(y)}$,

where $\operatorname{prob}\left(M_{i} \mid y\right)$ indicates posterior model probabilities, $\operatorname{prob}\left(y \mid M_{i}\right)$ is marginal likelihood, and $\operatorname{prob}\left(M_{i}\right)$ is the prior probability of model $i$. If the result of the marginal probability calculation has a value higher than the others, this will support the model selection.

c) Weight matrix:

In spatial models, weight matrices are exogenously imposed. The weight matrix $W$ is a nonnegative matrix that identifies the spatial relations between specified spatial units. The diagonal of the $W$ matrix is zero, which shows the exclusion of a self-neighbouring effect and is nonnegative otherwise. To avoid the singular values of the spatial autoregressive parameter, the weight matrix is normalized. Even though there are other methods, the most commonly used is row normalization. In row normalization, each element of the weight is divided by the sum of the related row of the weight matrix. According to the literature, the misspecification of the weight matrix will yield incorrect estimates. There are different approaches to correct this problem, but there have been no convincing results so far (see Lesage \& Pace, 2014). For greater objectivity, we tested different possible types of weight matrices. Some of the most commonly used weight matrices are those based on boundaries and distances, $k$-order binary contiguity matrices and $k$-order neighbour matrices: i) Binary weight matrices constructed on the neighbouring relations of the spatial units as one and zero. ii) $k$-order contiguity matrices 
are the generalization of the first-order contiguity weight matrix that shows if the neighbours share the same boundaries. In this study, we used a second-order contiguity weight matrix that shows the contiguity relations for the locations of neighbours to the first-order neighbour. iii) Construction of the weight as in many regional studies, we assumed that the space is Euclidean for the determination of the relation. The distance-based matrices and $k$-order neighbour matrices are constructed with the Euclidean distance between centroids of the two spatial units:

$d_{m n}=\sqrt{\left(\operatorname{lat}_{m}-\operatorname{lat}_{n}\right)^{2}+\left(\operatorname{long}_{m}-\operatorname{long}_{n}\right)^{2}}$,

where lat denotes latitude, long denotes longitude and $d_{m n}$ calculates the distance between spatial units $m$ and $n$. In the distance band weight matrix, the spatial weight matrix is created if $m$ is within the specified distance from $n$. More formally, $w_{m n}=1$, when $d_{m n} \leq d_{\max }$. Here, $d_{\max }$ is the specified distance, which covers many alternatives from $2 \mathrm{~km}$ to $30 \mathrm{~km}$ for this study. iv) $k$-order neighbour matrices are constructed on the neighbouring relations between their locations from a given spatial unit. These $k$-order effects help to capture the effects of all locations that are contiguous. After sorting out the distances between the spatial units, the weight matrix is constructed for a given $k$. In the study, from 1 to 20-nearest neighbours are used to construct a weight matrix based on whether spatial unit $m$ is in the centroids of given nearest centroids to $n$, regarding the structure is given in the previous part (iii).

\section{d) Preferred spatial model:}

According to the posterior model probabilities, the model is reduced to the SEM. SEM specifications reflecting spatial dependence in the disturbances and spatial error are indicative of omitted (spatially correlated) covariates that would affect inference if left unattended. Therefore, we present only the SEM to save space (for detailed explanations of the other models, please see Elhorst, 2013). If the general model, equation (1), is reduced to the SEM, $\delta$ and $\theta$ will be zero:

$$
\begin{aligned}
& Y=\alpha+X \beta+(I-\lambda W)^{-1} u, \\
& u=\lambda W u+\varepsilon, \quad \varepsilon \sim N\left(0, \sigma^{2} I\right),
\end{aligned}
$$

where $\lambda$ is the autoregressive parameter for the error term $W u, \varepsilon$ is generally an i.i.d. and spatially uncorrelated error term, $Y$ is an $\mathrm{N} \times 1$ vector of the dependent variable, $X$ is an $\mathrm{N} \times k$ matrix of observations of the explanatory variables, $\beta$ is the vector of parameters, and $W$, which includes a contiguity relation to the model, is an $\mathrm{N} \times \mathrm{N}$ symmetric matrix whose diagonal elements are 0 and whose off-diagonal elements are 1 . If $\lambda$ is equal to zero, there will be no spatial relations between the errors, and this will yield the ordinary least squares (OLS) model.

Unbiasedness will still hold in the SEM, whereas the regression coefficients will be inefficient if we estimate the model with OLS. In this study maximum likelihood estimation is used:

$\ln L\left(\beta, \lambda, \sigma^{2} \mid y, x\right)=-\frac{n}{2} \ln (2 \pi)-\frac{n}{2} \ln \sigma^{2}+\ln |I-\lambda W|-\frac{1}{2 \sigma^{2}} e^{\prime} e$,

where $e=(I-\lambda W)(y-x \beta)$. Considering all of the abovementioned economic and econometric structures, we estimated the model as follows:

$$
\begin{aligned}
\ln S= & \alpha+\beta_{1} \ln I N+\beta_{2} S E+\beta_{3} D M+\beta_{4} M E+\beta_{5} N F+\beta_{6} \ln M R+\beta_{7} \ln C S+\beta_{8} S H \\
& +\beta_{9} \ln P E+\beta_{10} \ln N T+\beta_{11} T M+\beta_{12} \ln A S+u .
\end{aligned}
$$

Explanations of abbreviations used in the above equation are given in Table 1. We used MATLAB codes, which are presented on the website of James LeSage (https://www.spatialeconometrics.com), and the codes of Paul Elhorst (https://spatial-panels.com/software/ and Yesilyurt and Elhorst, 2017). 


\subsection{Data Sets}

\subsubsection{Sample}

In this study, we reached out to 1700 of approximately 2800 students who were in the senior class in high schools in Denizli Province. However, some did not have an exam score because they had not taken the exam, and the quality of some of the questionnaires was not sufficient for the analyses. Therefore, we obtained 1083 usable questionnaires. Denizli Province is located southwest of Turkey, and its borders lie between the coordinates 37.841769, 29.043219; $37.724925,29.150715 ; 37.772910,28.995421$ and $37.785811,29.119884$. It had 17 towns at the time of this study. Descriptive statistics of variables are given in Table 1.

We administered three types of questionnaires. The first questionnaire covered questions about the students and their families. The second was a questionnaire regarding the students' school qualifications. The third was a questionnaire about their teachers' qualifications.

Table 1. Descriptive Statistics

\begin{tabular}{|c|c|c|c|}
\hline Variables & Number & Average & Standard deviation \\
\hline \multicolumn{4}{|l|}{ Dependent variable } \\
\hline $\ln ($ Entrance exam score- $S)$ & & 5.61 & 4.02 \\
\hline \multicolumn{4}{|l|}{ Explanatory variables } \\
\hline $\ln ($ Family income- $I N)$ & & 7.51 & 8.01 \\
\hline Education level of mother- $M E$ (from 1 to 5 ) & & 1.33 & 0.61 \\
\hline $\ln ($ Number of medical report days-MR) & & 2.2 & 1.94 \\
\hline $\ln ($ Class size- $C S)$ & & 3.23 & 1.95 \\
\hline ln (Previous year's average school score- $P E$ ) & & 5.55 & 3.56 \\
\hline $\ln ($ Number of teachers- $N T)$ & & 4.06 & 4.07 \\
\hline $\ln ($ Age of school- $A S)$ & & 3.04 & 2.73 \\
\hline Supplementary education-SE (=1) & 958 & & \\
\hline Student lives in dormitory-DM $(=1)$ & 126 & & \\
\hline Nuclear family-NF $(=1)$ & 744 & & \\
\hline There is a sports hall at school-SH $(=1)$ & 413 & & \\
\hline Teacher as manager-TM $(=1)$ & 64 & & \\
\hline
\end{tabular}

\subsubsection{Variables}

Explanations about variables are as follows:

\section{a) Dependent variable}

We used the Access to Higher Education Equal Weight of Math and Turkish Comprehension $(A H E-E W)^{\dagger}$ score. Because all students answer the same questions on this exam, the scores are comparable. This exam is provided to students when they are in their senior year of high school. The second exam, the UAE, is administered after students have graduated, which is why the results of the second exam may be impossible to collect. Even though we used the scores from the first exam, both scores represent achievement. These scores are more objective than the scores from students' high school exams in math, science, etc. Therefore, using the latter scores may not be ideal in every situation because the tests are administered and evaluated by different

\footnotetext{
$\dagger$ Yesilyurt and Say (2016) relied on similar data sets. However, their data were for students who aimed to maximize their math and science scores, while the present study uses data for students who aimed to maximize their math and Turkish comprehension scores equally. Additionally, the authors used the OLS estimator, while the present study uses spatial models in addition to OLS.
} 
teachers, and these results include the subjective perspective of teachers and may not be comparable for measuring student achievement.

In accordance with the majority of the literature, we used the AHE because it is general, objective, comparative and accepted by society. These types of standard and general test results/scores have been used in several studies, such as Sykes (2009) and Yesilyurt and Say (2016), to represent student achievement.

\section{b) Independent variables}

The pioneering report known as the Coleman Report (1966) attempted to understand what factors might affect students' achievement. The results suggest that school characteristics matter less than family background or peer effects. The report revealed the benefits of the integration of different groups of students on student achievement. Following this challenging work, researchers have attempted to understand and explain these effects. However, there is no consensus on the outcome and the directions of the effects.

Following this literature, the variables we tested are as follows:

I. Income of the family: One of the explanatory variables is the income of the family, which plays a role in student achievement. One of the reasons for this is that high-income families invest in resources for their children in early stages, which leads to an income-achievement gap that widens significantly after kindergarten (see Reardon, 2011). In the literature, for example, Duncan and Magnuson (2005) found a relationship between family income and achievement, especially for preschoolers and poor students. In this study, to assess family economic status, family income in Turkish lira is used.

II. The impacts of supplementary education: This is defined as all out-of-school-hours learning and is known as shadow education. It is becoming an important part of student achievement in competitive education systems. In the literature, various types of supplementary education have been found with different effects (see Tansel \& Bircan 2006; Maylor et al., 2010; Bray, 2013; Tansel, 2013; Wang \& Li, 2018). Supplementary education is common in countries that have nationwide examinations for access to higher levels of schooling (Tansel, 2013). We used a dummy variable for students who attended supplementary education.

III. Dormitory effect: Boarding/dormitory effects for college students are twofold. First, students are away from their homes and feel lonely and stressed, which has a negative effect (see Fisher et al., 1986). Second, these students are more likely to demonstrate non-attendance and tardiness, and the presence of their peers may produce positive effects. Particularly in Turkey, students live in a dormitory for numerous reasons. First, if a student's family is relatively poor but the student is not specifically unsuccessful, the student can live in a dormitory with most of the expenses paid by the government or certain charities. Second, if a student is granted entry to a specific school in another part of the country, he or she may live in a dormitory. In this case, families prefer dormitories, which are considered safe places for their children to live. To test this, we created a dummy variable with the value of 1 if a student lived in a dormitory during their education.

$I V$. Education level of mother: Researchers have found that family background is both directly and indirectly related to students' academic outcome. For example, Brenfenbronner (1994) stated that the family has vital importance for sustaining children's development. Some studies reveal that university-educated mothers and fathers have the same importance in students' performance (see Johnson et al., 1983; Aslund et al., 2011; Yesilyurt \& Say, 2016), whereas some studies conclude that the mother's education has a larger effect on adolescents (see Tansel \& Bircan, 2006). To test this structure, the education level of the mother was used as a categorical variable. 
$V$. Family structure: Even though living in a nuclear family is the standard, students may live in the same house with older members of the family or with a sibling's family in some conditions. People may prefer this arrangement because it saves money or preserves social control in the family. Certain families may particularly prefer this arrangement if they have newborn children because other members of the family, such as an aunt, grandmother or grandfather, can take care of the children. Opposite effects may arise with regard to student achievement: The first is the negative effect of a crowded home, and the second is the positive effect of warm, supportive conditions at home. In this study, we observed which effect was valid, specifically in Denizli/Turkey. Parke (2003) found that children reared in nuclear families do better than those in stable blended families; however, when controlling for other effects, this effect becomes weak. To test this structure, we used a dummy variable with the value of 1 if the student lived in nuclear family and 0 otherwise.

VI. Student health: Mental and physical health has a relationship with adolescents' academic outcomes, and the number of days a student is absent due to health issues may be an indicator of an unhealthy situation. This may affect students' performance directly because poor health causes non-attendance and class failure (see Salle \& Sanetti, 2016) and indirectly because they cannot form social bonds (see Way et al., 2007; Niehaus et al., 2012). The number of days absent because of health issues can be used to test the effect of student health on achievement.

Additionally, we tested several variables related to school and classroom conditions. Researchers have attempted to analyse the effect of school conditions on the achievement gap. Hopland (2012) found a negative relation between poor building conditions and student achievement in Norway. These variables are as follows:

VII. Class size: Some researchers have found a positive relationship between student achievement and class size (see Urquiola, 2001), whereas others have found no relation (Hoxby, 2000).

VIII. Sports hall in school: High school students are very active, and they need to release their energy. Schools with a sports hall may help students release energy safely (MacGowenn, 2007; Huesman et al., 2007; Murillo \& Roman, 2011). We used a dummy variable with the value of 1 if there was a sports hall in the school and 0 otherwise.

$I X$. Previous year's average school score: We included this variable to determine whether achievement is continuous and to generalize whether students benefit from the school's perspective.

$X$. The number of teachers in the school: This control variable represents human capital, abundant expert teachers and the substitutability between teachers.

$X I$. Teacher as manager: This control variable is a dummy variable that represents whether at least one of a student's teachers is a manager at school ( 1 if so, otherwise 0$)$. Being a manager at school may be a time-consuming job; therefore, if a teacher is a manager, he or she may not focus on education.

XII. Age of school: Studies have also investigated the relationship between the age of the school building and student achievement (O’Neill \& Oates, 2001).

\section{RESULT / FINDINGS}

Before conducting the tests for spatial models, we performed general to specific modelling using the OLS estimator. In these estimations, we eliminated the most insignificant variable each time and estimated the model again until all variables were significant. Estimation procedures after OLS are provided in the following section, and the tests are explained step by step. Then, we performed testing to determine which weight matrix and spatial model best fit the data set based on Bayesian posterior probabilities (BPPs). We applied the test in several 
steps. In the first step, alternative weight matrices were investigated for different spatial models. In the second step, SAR, SEM and SDM models with their best weight matrices were compared with each other to derive the conclusion.

The weight matrices that we tested for each model were the binary matrix, second-order contiguity matrix, from 1 to 20 nearest neighbours and from $1 \mathrm{~km}$ to $30 \mathrm{~km}$ of distance band between the students' houses. Since we created many nearest neighbour weight matrices and many distance weight matrices, we estimated the best fit nearest neighbour weight matrix and spatial model (against SEM, SAR and SDM) combination and the best fit distance weight matrix and spatial model combination (against SEM, SAR and SDM) first. Then compared these combinations of distance and neighbour weight matrices to the binary contiguity and second order weight matrix.

According to the tests applied, the best fit nearest weigh matrix and spatial model combination is 16 nearest neighbours for SAR, SEM and SDM. However, for the distance matrices, different weight matrices fit different spatial models. The weight matrix of neighbours within $18 \mathrm{~km}$ fits the SAR model, $2 \mathrm{~km}$ fits the SEM and $20 \mathrm{~km}$ fits the SDM.

Table 2 presents these comparisons. The bold parts in the table show the alternatives tested in this step. The alternatives W3, W4, W5 and W6 were determined in the previous step to be the best fit combinations.

Table 2. Model selection

\begin{tabular}{lccc}
\hline & SAR & SEM & SDM \\
\hline W1 (binary contiguity) & $\mathbf{0 . 0 0 0}$ & $\mathbf{0 . 0 0 0}$ & $\mathbf{0 . 0 0 0}$ \\
W2 (second-order contiguity) & $\mathbf{0 . 0 0 0}$ & $\mathbf{0 . 0 0 0}$ & $\mathbf{0 . 0 0 0}$ \\
W3 (16 nearest neighbour) & 0.000 & $\mathbf{1 . 0 0 0}$ & 0.000 \\
W4 (neighbours within 18 km) & $\mathbf{0 . 0 0 0}$ & 0.000 & 0.000 \\
W5 (neighbours within 2 km) & 0.000 & $\mathbf{0 . 0 0 0}$ & 0.000 \\
W6 (neighbours within 20 km) & 0.000 & 0.000 & $\mathbf{0 . 0 0 0}$ \\
\hline
\end{tabular}

According to the BBP test that compares the best weight matrices for distance and nearest neighbours in addition to binary and second-order contiguity, 16 nearest neighbour weight matrices with SEM gives the best-combination for the data set. Therefore, we estimated spatial regressions using W3 with SEM.

The use of the 16 nearest neighbour matrices instead of a distance matrix may be understandable because it is usually not possible to restrict the interaction of people based on distance. Occasionally, certain neighbours cannot interact and encounter one another despite being very close because some streets do not intersect.

After the selection of the best model and the weight matrix, another important issue is whether there is any misspecification problem in the model. Lesage and Pace (2014) proposed a Hausman test to test whether the OLS and SEM estimates are significantly different. This test is used in the case of inefficient but consistent OLS parameter estimates and efficient estimates of SEM. To be sure that SEM is superior to OLS, we used this test. The results indicate whether there is misspecification in the model. We applied this test, and its result of 26.24 with a 0.19 marginal probability did not diagnose any problem; therefore, we could estimate the SEM. According to the regression results, even though many parameters were similar, there are some differences. For example, income was significant at the 0.1 in OLS but it is insignificant in SEM; living in the dormitory was significant at the 0.1 in OLS, but it is also significant at the 0.05 in SEM. Therefore, the test points SEM, the parameters in SEM should be considered. 
Additionally, if the SEM results were ignored, the interaction between students could not be considered to help in understanding the students' reality.

Based on all the processes and tests discussed above, we did not find evidence supporting the first two hypotheses. In other words, SAR and SDM were always rejected in favour of the SEM, and we found evidence of significant spatial dependence.

Before discussing the estimation results of the explanatory variables, we discuss the general importance of interaction among students. The interaction relationships among students were confirmed by econometric tests that allowed us to investigate and discuss two important issues. First, because the SEM considers interactions among error terms, the results of the estimation confirm that there is interaction in terms of the unobservable and/or uncovered factors in the model with regard to student achievement. One of the most difficult issues when analysing social interaction and its effects is that it is nearly impossible for some variables to be measured and observed. However, according to the estimation results, the interaction parameter, lamda, is positive and highly significant. As a result, these data sets suggest that there is dependence in the disturbance process. Second, the SEM is able to address this issue because the error term can cover unobserved and unmeasured variables. Understanding these interaction effects may provide an alternative way for policy makers to achieve "optimal organisation of school(s), jobs and neighbourhoods" (Hoxby, 2000). Based on the preferred weight matrix, the SEM estimation results are given in Table 3.

Table 3. Estimation results

\begin{tabular}{|c|c|c|}
\hline & SEM & OLS \\
\hline & Coefficient (t-ratio) & Coefficient (t-ratio) \\
\hline$R^{2}$ & 0.3424 & 0.2885 \\
\hline Log-likelihood & 721.66 & 321.96 \\
\hline Constant & $3.45(13.99)^{* * *}$ & $3.19(13.15)^{* * *}$ \\
\hline $\ln ($ Income- $I N)$ & $0.01(1.09)$ & $0.01(1.64)^{*}$ \\
\hline Supplementary education- $S E$ & $0.13(7.84)^{* * *}$ & $0.14(7.91)^{* * *}$ \\
\hline Student lives in dormitory- $D M$ & $0.04(2.27)^{* *}$ & $0.03(1.72)^{*}$ \\
\hline Education level of mother $-M E$ & $0.03(2.88)^{* * *}$ & $0.03(3.27)^{* * *}$ \\
\hline Nuclear family-NF & $0.03(2.66)^{* * *}$ & $0.03(2.84)^{* * *}$ \\
\hline $\ln ($ Number of medical report days- $M R$ ) & $-0.01(-2.28)^{* *}$ & $-0.01(-2.14)^{* *}$ \\
\hline $\ln ($ Class size- $C S)$ & $-0.08(-3.26)^{* * *}$ & $-0.06(-2.71)^{* * *}$ \\
\hline There is a sports hall at school-SH & $0.09(7.19)^{* * *}$ & $0.08(5.93)^{* * *}$ \\
\hline $\ln$ (Previous year's average school score- $P E$ ) & $0.36(7.73)^{* * *}$ & $0.40(8.68)^{* * *}$ \\
\hline $\ln ($ Number of teachers- $N T)$ & $0.07(7.22)^{* * *}$ & $0.06(6.19)^{* * *}$ \\
\hline Teacher as manager-TM & $-0.05(-1.76)^{*}$ & $-0.05(-1.87)^{*}$ \\
\hline $\ln ($ Age of school- $A S)$ & $-0.04(-4.65)^{* * *}$ & $-0.05(-5.91)^{* * *}$ \\
\hline lamda & $0.50(9.60)^{* * *}$ & \\
\hline
\end{tabular}

*significant at $10 \%,{ }^{* *}$ significant at $5 \%,{ }^{* * *}$ significant at $1 \%$.

According to Table 3, average income had a positive effect on student achievement but was insignificant. We expected that this variable would positively contribute to and have a significant effect on student achievement based on the literature (Duncan et al., 1998; Stipek, 1998; Tansel, 2002; Dubow et al., 2009). On the other hand, in countries such as Turkey, councils or other governmental organizations help and transfer money to poor families to ensure balanced income levels. 
Another important variable in this literature is supplementary education (Karweit \& Slavin, 1981), and this variable was positive and significant in the present study. Supplementary education is one of the most controversial issues in the literature, especially in certain countries, and it is a practice that "has long been ingrained in the cultures of East Asia, and is now increasingly evident in West and Central Asia, in Europe, in North America, and in Africa" (Bray, 2013). For example, Yaylalı et al. (2006) found evidence supporting these finding results for Turkey that were similar to those Kang (2007) observed in Korea. On the other hand, it is ideal for schools to be able to provide knowledge to all students, and an education system should not necessarily be attached to an organization. Additionally, this may indicate that school syllabuses should be revised to improve the motivation and attitude of students.

One of the most attractive variables is living in a dormitory. In Turkey, political/charity organizations in addition to the government establish dorms and invite students to live in them during their education, or higher-quality schools, which are not available in every town, offer dormitory space to students who want to attend these schools. Therefore, families that live in distant villages and towns tend to allow their children to live in dormitories to prevent their students from being spoiled or to enable the students to attend better schools located far from their towns. In these dorms, senior students and other tutors help students with their lessons. Therefore, we found a positive contribution of living in a dorm to academic achievement, as expected.

We used the nuclear family as an explanatory variable for student achievement because the literature provides evidence for this link. Our positive significant results confirmed previous results (Booth \& Kee, 2006). When we focus on family structure in Turkey, some cultural issues should be considered. In Turkey, particularly in less developed regions and in distant areas, some parents tend to live with brothers, sisters, fathers and mothers or some parts of the family. Elderly members of a broader family may have noticeable authority over children. This structure may restrict children's progress and independence and thus their achievement. Conversely, a larger family may be useful because family members help each other. For example, a grandmother can take care of her grandchildren when their mother is away. Additionally, children may thrive in warmer and more supportive conditions. Consequently, according to our data set, living in a nuclear family is a positive significant sign, and it seems that the first argument is more dominant for student achievement.

Another key factor in determining student achievement is parents' education level. In the literature, the educational level of both parents or one parent usually has a positive effect on student achievement (Brooks-Gunn et al., 1993; Dincer \& Uysal, 2010; Aslund et al., 2011; Yesilyurt \& Say, 2016). Particularly until the beginning of school, the family contributes to a student's perspective, understanding and logical progress. Thus, parents can transmit signs, messages and expectations from the modern and improving world to their children, which serve as important leverage for children. In this study, we found that maternal educational level positively impacts student achievement.

We proxied the number of days students did not attend class because of physical or mental health issues, which may decrease students' capacity. According to the literature, students who are unhealthy are at higher risk for school problems than students who are free from medical problems (Needham et al., 2000; Spernak et al., 2006; Shaw et al., 2015). Mental and physical discomfort and uneasiness restrict student capacity and targets (Fowler et al., 1992). Our results confirm that students with a higher number of missing days had lower levels of achievement.

Another group of variables is school-related factors. These are important because the literature presents some opposite results about the physical conditions of schools, even though the dominant understanding favours better physical factors (Shapson et al., 1980; Correa, 1993; Blatchford \& Mortimore, 1994; Akerhielm, 1995). One school-related factor is the school's 
age, which is used to measure whether the school culture contributes to student achievement. An older school may have a positive culture and discipline to help students achieve positive outcomes. On the other hand, if the school tradition has degenerated, it may negatively affect students over time. Conversely, a young school may have undisciplined practices, although it may encourage the use of new and useful technologies. A new school with new technology, good conditions and a new perspective may positively contribute to student achievement. According to our results, students in younger schools are more successful. Another schoolrelated variable is class size, which negatively affects student achievement. This finding is understandable because when the class size is large, students may not feel comfortable in the class, and teachers may not care about engaging with students effectively (Hanushek, 1997; Hoxby, 2000; Urquiola 2001). The third school-related factor is that the presence of a sports centre at school is associated with more successful students. High school students are very dynamic and need to release their energy, and a sports centre may be an effective means of doing so (MacGowenn, 2007; Huesman et al., 2007; Murillo \& Roman, 2011).

Two teacher-related factors are included in our final model. The first is the number of teachers in school with a significant positive sign. This variable is interesting and may affect students in two ways. First, if there are more teachers in a school, there are likely to be more specialist teachers. Second, competition between teachers is likely to exist. Principals who are responsible to the provincial director of education exert pressure on teachers to be more successful. Therefore, having more teachers in a school may improve teacher performance. The second teacher-related factor is being a manager in a school that requires major effort. If a teacher serves as a manager in the school in addition to being a teacher, he or she may not exhibit maximal teaching performance.

The last variable included in our final models is average university entrance exam score from the previous year, which has a positive significant sign and may determine the sustainability of achievement.

\section{DISCUSSION and CONCLUSION}

In this study, we estimated student academic achievement and the contribution of spatial models. The spatial weight matrix was determined objectively by utilizing Bayesian criteria. Through testing, we determined that the 16 nearest students and the SEM were the best-fitting combination for estimation.

The interaction parameter of the SEM estimation had a positive and significant result. This provides evidence that interaction is important in terms of students' achievement and investment in the student learning environment. This may be because any improvements to neighbours will contribute to focal students through their interaction with their neighbours' children. As a result, these data sets suggest that student achievement is contagious, and improving these aspects for students is crucial. Therefore, policy makers may want to invest in the learning environment to benefit students and to achieve the interaction effects among students identified in this study.

More specifically, similar to the previous literature, we found contributions of maternal education level, living in a nuclear family and some school-specific factors, such as a young school and small class size. In Turkey, women's mean years of schooling is lower than that of men. It seems that efforts to promote women's intellectual level through formal or informal education would be effective for improving student achievement. Although some literature claims that school-related factors do not affect student achievement as much as other factors, we found evidence that schools that are more comfortable, young, and endowed with new technologies promote student achievement. 


\section{Acknowledgements}

The authors thank Ron Smith (Birkbeck College), two anonymous reviewers, and Eren Can Aybek (IJATE's Editor) for their useful comments.

This research was supported by Pamukkale University Scientific Research Projects Coordination Unit under grant number 2011SOBE047, for which the authors are indebted.

\section{Declaration of Conflicting Interests and Ethics}

The authors declare no conflicts of interest. This research study complies with research publishing ethics. The scientific and legal responsibility for manuscripts published in IJATE belongs to the author(s).

\section{ORCID}

Filiz Akbaş-Yeşilyurt (iD https://orcid.org/0000-0003-1629-4747

Hüseyin Koçak (iD https://orcid.org/0000-0001-9683-6096

M. Ensar Yeşilyurt (D) https://orcid.org/0000-0001-5610-3146

\section{REFERENCES}

Aaronson, D. (1998). Using sibling data to estimate the impact of neighborhoods on children's educational outcomes. Journal of Human Resources, 33, 915-946. https://doi.org/10.230 $7 / 146403$

Adejoro, O. E. (2016), Does location also matter? A spatial analysis of social achievements of young south Australians [Unpublished Master Thesis]. Department of Physical Geography and Ecosystem Science, Lund University, Lund, 2016.

Akerhielm, K. (1995). Does class size matter?. Economics of Education Review, 14(3), 229241. https://doi.org/10.1016/0272-7757(95)00004-4

Akerlof, G. A. (1997). Social distance and social decisions. Econometrica, 65(5), 1005-1027. https://doi.org/10.2307/2171877

Anselin, L. (1988). Spatial Econometrics: Methods and Models. Springer Science \& Business Media.

Aslund, O., Edin, Per-Anders, Fredriksson, P., \& Grönqvist, H. (2011). Peers, neighborhoods, and immigrant student achievement: evidence from a placement policy. American Economic Journal: Applied Economics, 3(2), 67-95. https://doi.org/10.1257/app.3.2.67

Bayer, P., Hjalmarsson, R., \& Pozen, D. (2009). Building criminal capital behind bars: Peer effects in juvenile corrections. The Quarterly Journal of Economics, 124(1), 105-147. https://doi.org/10.3386/w12932

Bernheim, B. D. (1994). A theory of conformity. Journal of Political Economy, 102, 841-877. https://doi.org/10.1086/261957

Blatchford, P., \& Mortimore, P. (1994). The issue of class size for young children in schools: What can we learn from the research?. Oxford Review of Education, 20(4), 411-428. https://doi.org/10.1080/0305498940200402

Booth, A., \& Kee, H. (2006). Birth order matters: The effect of family size and birth order on educational attainment. Journal of Population Economics, 22(2), 367-397. https://doi.or $\mathrm{g} / 10.1007 / \mathrm{s} 00148-007-0181-4$

Brannstrom, L. (2008). Making their mark: The effects of neighbourhood and upper secondary school on educational achievement. European Sociological Review, 24(4), 463-478. https://doi.org/10.1093/esr/jen013

Bray, M. (2013). Shadow education: comparative perspectives on the expansion and implications of private supplementary tutoring. Procedia - Social and Behavioral Sciences, 77(22), 412-420. https://doi.org/10.1016/j.sbspro.2013.03.096 
Brock, W. A., \& Durlauf, S. N. (2001). Discrete choice with social interactions. The Review of Economic Studies, 68(2), 235-260. https://doi.org/10.1111/1467-937X.00168

Bronfenbrenner, U. (1994). Ecological models of human development. Readings on the Development of Children, 2(1), 37-43.

Brooks-Gunn, J., Duncan, G. J., Klebanov, P. K., \& Sealand, N. (1993). Do neighborhoods influence child and adolescent development?. American Journal of Sociology, 99, 35395. https://doi.org/10.1086/230268

Coleman, J. S. (1961). The adolescent society: the social life of the teenager and its impact on education. Free Press of Glencoe.

Correa, H. (1993). An economic analysis of class size and achievement in education. Education Economics, 1(2), 129-35. https://doi.org/10.1080/09645299300000019

Dietz, R. D. (2002). The estimation of neighborhood effects in the social sciences: An interdisciplinary approach. Social Science Research, 31(4), 539-575. https://doi.org/10.1 016/S0049-089X(02)00005-4

Dincer, M. A. \& Uysal, G. (2010). The determinants of student achievement in Turkey, International Journal of Educational Development, 30(6), 592-598. https://doi.org/10.1 016/j.ijedudev.2010.05.005

Dubow, E.F., Boxer, P., \& Huesmann, L. R. (2009). Long-term effects of parents' education on children's educational and occupational success: Mediation by family interactions, child aggression, and teenage aspirations, Merrill-Palmer Quarterly, 55(3), 224-249. https://doi.org/10.1353/mpq.0.0030

Duncan, G. J., Yeung, W. J., Brooks-Gunn, J., \& Smith, J. R. (1998). How much does childhood poverty affect the life chances of children?. American Sociological Review, 63(3), 406423. https://doi.org/10.2307/2657556

Duncan, G., \& Magnuson, K. (2005). Can family socioeconomic resources account for racial and ethnic test score gaps?. Future of Children, 15(1), 35-54. https://doi.org/10.1353/fo c.2005.0004

Duncan, G J. (1994). Families and neighbors as sources of disadvantage in the schooling decisions of black and white adolescents. American Journal of Education, 103(1), 20-53. https://doi.org/10.1086/444088

Elhorst, J. P. (2010). Dynamic panels with endogenous interaction effects when $T$ is small, Regional Science and Urban Economics, 40(5), 272-282. https://doi.org/10.1016/j.regsc iurbeco.2010.03.003

Elhorst, J. P. (2013). Spatial Econometrics: From Cross-Sectional Data to Spatial Panels. Springer-Verlag.

Elhorst, P., Zandberg, E., \& de Haan, J. (2013). The impact of interaction effects among neighbouring countries on financial liberalization and reform: A dynamic spatial panel data approach. Spatial Economic Analysis, 8(3), 293-313. https://doi.org/10.1080/17421 772.2012.760136

Ertur, C., \& Koch, W. (2007). Growth, technological interdependence and spatial externalities: Theory and evidence. Journal of Applied Econometrics, 22(6), 1033-1062. https://doi.or $\mathrm{g} / 10.1002 / \mathrm{jae} .963$

Evans, W. N., Oates, W. E., \& Schwab, R. M. (1992). Measuring peer group effects: A study of teenage behavior. The Journal of Political Economy, 100(5), 966-991. https://doi.org/10.1086/261848

Farber, A., Huu Tu, N., Tran, D., \& Vuong, Q. H. (2008). The financial storms in Vietnam's transition economy: A reasoning on the 1991-2008 period. Working Papers CEB, ULB.

Fisher, S., Frazer, N. \&Murray, K. (1986). Homesickness and health in boarding school children. Journal of Environmental Psychology, 6(1), 35-47. https://doi.org/10.1016/S0 272-4944(86)80033-0 
Fowler, M. G., Davenport, M. G., \& Garg, R. (1992). School functioning of US children with asthma. Pediatrics, 90(6), 939-944.

Gibbons, S., Silva, S., \& Weinhardt, F. (2013). Everybody needs good neighbours? Evidence from students' outcomes in England. The Economic Journal, 123(571), 831-874. https://doi.org/10.1111/ecoj.12025

Gould, E., Lavy, V., \& Paserman, S. D. (2009). Sixty years after the magic carpet ride: The long-run effect of the early childhood environment on social and economic outcomes. Review of Economic Studies, 78(3), 938-973. https://doi.org/10.3386/w14884

Hanushek, E. A. (1997). Assesing the effect of school resources on student performace: An update. Educational Evoluation and Policy Analysis, 19(2), 141-164. https://doi.org/10. $\underline{3102 / 01623737019002141}$

Hanushek, E. A. (1979). Conceptual and empirical issues in the estimation of educational production functions. Journal of Human Resources, 14(3), 351-88. https://doi.org/10.23 $07 / 145575$

Heck, R. H. (2009). Teacher effectiveness and student achievement: Investigating a multilevel cross-classified model. Journal of Education Administration, 7(22), 227-249. https://doi.org/10.1108/09578230910941066

Hopland, A. O. (2012). School Building Conditions and Student Achievement: Norwegian Evidence. Working Paper No. 2/2012, Department of Economics, Norwegian University of Science and Technology.

Hoxby, C. M. (2000). Peer Effects in the Classroom: Learning from Gender and Race Variation, NBER Working Paper no. 7867, National Bureau of Economic Research.

Hsieh, C. S., \& Lin, X (2019), Social Interactions and Social Preferences in Social Networks, Working Paper.

https://spatial-panels.com/software/, (15.06.2018)

https://www.spatial-econometrics.com/, (15.06.2018)

Huesman, R L. Jr, Brown, A. K., Lee, G., Kellogg, J. P., \& Radcliffe, P. M. (2007). Modeling Student Academic Success: Does Usage of Campus Recreation Facilities Make a Difference?. Retrieved from the University of Minnesota Digital Conservancy, http://hdl.handle.net/11299/159766, (30.03.2017)

Jensen, B., \& Harris, M. N. (2008). Neighbourhood measures: quantifying the effects of neighbourhood externalities. The Economic Record, 84(264), 68-81. https://doi.org/10.1 111/j.1475-4932.2008.00447.x

Johnson, R. C., Nagoshi, C. T., Ahren, F. M., Wilson, J. R., DeFries, J. C., \& McClearn, G. E. (1983). Family background, cognitive ability, and personality as predictors of educational and occupational attainment. Social Biology, 30(1), 86-100. https://doi.org/10.1080/194 $\underline{85565.1983 .9988519}$

Kang, C. (2007). Does Money Matter? The Effect of Private Educational Expenditures on Academic Performance, Departmental Working Papers, National University of Singapore, Department of Economics.

Karweit, N., \& Slavin, R. E. (1981). Measurement and Modelling Choices in Studies of Time and Learning. American Educational Research Journal, 18(2), 157-171. https://doi.org/ $10.3102 / 00028312018002157$

Lavy, V., \& Schlosser, A. (2011). Mechanisms and impacts of gender peer effects at school. American Economic Journal: Applied Economics, 3(2), 1-33. https://doi.org/10.1257/ap p.3.2.1

LeSage, J. P. (2014). Spatial econometric panel data model specification: A Bayesian approach. Spatial Statistics, 9, 122-145. https://doi.org/10.1016/j.spasta.2014.02.002

LeSage, J. P., \& Pace, K. (2014). The Biggest Myth in Spatial Econometrics. Econometrics, 2 (4), 217-249. https://doi.org/10.3390/econometrics2040217 
LeSage, J. P. (2015). Software for Bayesian cross section and panel spatial model comparison. Journal of Geographical Systems, 17(4), 297-310. https://doi.org/10.1007/s10109-015$\underline{0217-3}$

MacGowenn, R. S. (2007). The Impact of School Facilities on Student Achievement, Attendance, Behavior, Completion Rate and Teacher Turnover Rate in Selected Texas High Schools, PhD Thesis, Texas A\&M Universities.

Manski, C. F. (2000). Economic analysis of social interactions. Journal of Economic Perspectives, 14(3), 115-136. https://doi.org/10.1257/jep.14.3.115

Manski, C. M. (1993). Identification of endogenous social effects: The reflection problem. Review of Economic Studies, 60(3), 531-542. https://doi.org/10.2307/2298123

Matlock, K., Song, J. J. \& Goering, C. Z. (2014). Spatial dependency and contextual effects on academic achievement, International Journal of Educational Administration and Policy Studies, 6(3), 32-42. https://doi.org/10.5897/IJEAPS2013.0327

Mayer, S., \& Jencks, C. (1989). Growing up in poor neighborhoods: How much does it matter? Science, 243(4897), 1441-1445. https://doi.org/10.1126/science.243.4897.1441

Maylor, U., Glass, K., Issa, T, Kuyok, K. A., Minty, S. Rose, Anthea. Ross, Alistair, Tanner, E., Finch, S., Low, N., Taylor, E., Tipping, S., Purdon, (2010). Impact of Supplementary Schools on Pupils' Attainment: An Investigation into what Factors Contribute to Educational Improvements, Research Reports, London: DSCF, (12.07.2018)

Mizruchi, M. S., \& Neuman, E. J. (2008). The effect of density on the level of bias in the network autocorrelation model. Social Networks, 30(3), 190-200. https://doi.org/10.101 6/j.socnet.2008.02.002

Moffitt, R. A. (2001). Policy Interventions, Low-level Equilibria, and Social Interactions, in Social Dynamics, edited by S. Durlauf and P. Young. MIT Press.

Murillo, F. J., \& Román, M. (2011). School infrastructure and resources do matter: analysis of the incidence of school resources on the performance of Latin American students. School Effectiveness and School Improvement, 22(1), 29-50. https://doi.org/10.1080/09243453. 2010.543538

Needham, B. L., Crosnoe, R., \& Muller, C. (2004). Academic failure in secondary school: The inter-related role of health problems and educational context. Social Problems, 51(4), 569-586. https://doi.org/10.1525/sp.2004.51.4.569

Niehaus, K., Rudasill, K. M., \& Rakes, C. R. (2012). A longitudinal study of school connectedness and academic outcomes across sixth grade. Journal of School Psychology, 50(4), 443-460. https://doi.org/10.1016/j.jsp.2012.03.002

O'Neill, D., \& Oates, A. (2001). The impact of school facilities on student achievement, behavior, attendance, and teacher turnover rate in central texas middle schools. Educational Facility Planner, 36(3), 14-22.

Paelinck, J., \& Klaassen, L. (1979). Spatial Econometrics. Saxon House.

Parke, M. (2003). Are Married Parents Really Better for Children? What Research Says About The Effects of Family Structure On Child Well-Being. Research Paper, Center for Law and Social Policy.

Reardon, S. F. (2011). The Widening Socioeconomic Status Achievement Gap: New Evidence and Possible Explanations. In Whither opportunity? Rising Inequality and the Uncertain Life Chances of Low-Income Children, R. J. Murnane and G. J. Duncan (Eds.), Russell Sage Foundation.

Shapson, S. M., Wright, E. N., Eason, G., \& Fitzgerald, J. (1980). An experimental study of the effects of class size. American Educational Research Journal, 17(2), 141-152. https://doi.org/10.3102/00028312017002141 
Shaw, S. R., Gomes, P., Polotskaia, A. \& Jankowska, A. M. (2015). The relationship between student health and academic performance: Implications for school psychologists. School Psychology International, 36(2), 115-134. https://doi.org/10.1177/0143034314565425

Spernak, S. M., Schottenbauer, M. A., Ramey, S. L., \& Ramey, C. T. (2006). Child health and academic achievement among former head start children. Children and Youth Services Review, 28(10), 1251-1261. https://doi.org/10.1016/j.childyouth.2006.01.006

Stakhovych, A., \& Bijmolt, T. H. A. (2009). Specification of spatial models: A simulation study on weights Matrices. Regional Science, 88(2), 389-408. https://doi.org/10.1111/j.14355957.2008.00213.x

Stipek, D. (1998). Motivations to Learn: From Theory to Practice. $4^{\text {th }}$ edition, Allyn and Bacon.

Sykes, B. (2009). Spatial Order and Social Position: Neighbourhoods, Schools and Educational Inequalit. [Unpublished doctoral dissertation]. Amsterdam Institute for Social Science Research

Sykes, B., \& Kuyper, H. (2009). Neighbourhood effects on youth educational achievement in the netherlands: Can effects be identified and do they vary by student background characteristics?. Environment and Planning A, 41, 2417-2436. https://doi.org/10.1068/a $\underline{41255}$

Tansel, A., \& Bircan, F. (2006). Demand for education in Turkey: A Tobit Analysis of Private Tutoring Expenditures in Turkey. Economics of Education Review, 25, 303-313. https://doi.org/10.1016/j.econedurev.2005.02.003

Tansel, A. (2002). Determinants of Schooling Attainment for boys and girls in Turkey. Economics of Education Review, 21(5), 455-470. https://doi.org/10.1016/S02727757(01)00028-0

Tansel, A., (2013). Supplemantary Education in Turkey: Recent Developments and Future Prospects, Koç University-TUSIAD Economic Research Forum Working Paper Series.

Todd, P. E., \& Wolpin, K. I. (2003). On the specification and estimation of the production function for cognitive achievement. Economic Journal, 113(485), F3-F33. https://doi.org/10.1111/1468-0297.00097

Wang, J., \& Li, B. (2018). Supplementary education, student development and education equity: Evidence from primary schools in Beijing-China. Education Economics, 26(5), 459-487. https://doi.org/10.1080/09645292.2018.1460653

Way, N., Reddy, R., \& Rhodes, J. (2007). Students' perceptions of school climate during the middle school years: Associations' with trajectories of psychological and behavioral adjustment. American Journal of Community Psychology, 40, 194-213. https://doi.org/1 $\underline{0.1007 / \mathrm{s} 10464-007-9143-\mathrm{y}}$

Weinhart, F. (2014). Social housing, neighborhood quality and student performance. Journal of Urban Economics, 82, 12-31. https://doi.org/10.1016/j.jue.2014.06.001

Winship, C., Harding, D. J., Gennetian, L., Sanbonmatsu, L., \& Kling, J. (2011). Unpacking Neighborhood Influences on Education Outcomes: Setting the Stage for Future Research. In: Opportunity? Rising Inequality, Schools and Children's Life Chances; Edited by Duncan G and Whither, M. R.

Yaylalı, M., Kızıltan, A., Oktay, E., Doğan, E. M., Özer, H., Naralan, A., Özen, Ü., Özçomak, M. S., Akan, Y., \& Aktürk, E. (2006). Üniversite Gençliğinin Gelir-Harcama Kalıpları Araştırması. [Survey of Income-Spending Patterns of University Students]. Ataturk University Publication, Erzurum

Yesilyurt, M. E., \& Say, D. (2016). Factors affecting success of high school students in Turkey. Ege Academic Review, 16(3), 541-554.

Yesilyurt, M. E., \& Elhorst, J. P. (2017). Impacts of neighboring countries on military expenditures: A dynamic spatial panel approach. Journal of Peace Research, 54(6), 777790. https://doi.org/10.1177/0022343317707569 
Yeşilyurt, M. E., Karadeniz, O., Gülel, F. E., Çağlar, A., \& Kangall1-Uyar, S. G. (2016). Türkiye'de Illlere Göre Ortalama ve Beklenen Okullaşma Y11, [Mean and expected years of schooling for provinces in Turkey]. Pamukkale Journal of Eurasian Socioeconomics Studies, 3(1), 1-7. https://doi.org/10.5505/pjess.2016.55706

Yeşilyurt, F., Koçak, H., \& Yeşilyurt, M. E. (2020). Factors Determining the Development of Minimum Comparable Areas and Spatial Interaction. Submitted.

Zangger, C. (2016), The Spatial Structure of Educational Achievement, Researchgate.net.

Zavarrone, E., \& Vitali, A. (2012). School Performance and Network Effects among Classmates. Population Association of America 2012 Annual Meeting.

Zimmerman, D. J. (2003). Peer effects in academic outcomes: evidence from a natural experiment. Review of Economics and Statistics, 85(1), 9-23. https://doi.org/10.1162/00 $\underline{3465303762687677}$ 